IJBPAS, January, Special Issue 2, 2022, 11(1): 680-689

ISSN: 2277-4998

International Journal of Biology, Pharmacy and Allied Sciences (IJBPAS)

'A Bridge Betueen Caboratory and Q Qnder'

www.ibpas.com

\title{
GROWTH AND CHARACTERIZATION OF EFFICIENT SEMI- ORGANIC SINGLE CRYSTAL OF ADIPIC ACID COBALT NITRATE
}

\author{
K. SURESH ${ }^{*}$, R.S. SUNDARARAJAN ${ }^{1}$, V.S.KUMAR ${ }^{2}$
}

1: Department of Physics, Government Arts College (Affiliated to Bharathidasan University), Kumbakonam, Tamilnadu, India.

2: Department of Physics, Swami Dayananda College of Arts and Science (Affiliated to Bharathidasan University), Manjakkudi, Tamilnadu, India *Corresponding Author: K. Suresh: E Mail: sureshiths@gmail.com Received $3^{\text {rd }}$ Oct. 2021; Revised $11^{\text {th }}$ Nov. 2021; Accepted $20^{\text {th }}$ Dec. 2021; Available online $25^{\text {th }}$ Jan. $_{2022}$ https://doi.org/10.31032/ijbpas/2022/11.1.2067

\section{ABSTRACT}

In this article, the reports pertaining to growth of single crystals of Adipic acid Cobalt nitrate by slow evaporation solution growth technique and its characterization. The optical transmittance of the grown AACON was measured by UV-Vis-NIR analysis. Fluorescence studies set out the spectral distribution of emitted light with various colors in AACON crystal. The peaks recorded in the PXRD gives the crystalline nature of AACON. The various functional groups present in the grown crystal and its purity have been taken apart by FT-IR and FTRaman. The non linear optical property of AACON crystal was examined by second harmonic generation test using Nd:YAG laser of wavelength $1064 \mathrm{~nm}$.

Keywords: Adipic acids, Cobalt nitrate, crystal growth, UV-Vis-NIR spectrum, Fluorescence studies, Powder X-ray diffraction analysis, FT-IR and FT-Raman spectra, SHG test \section{INTRODUCTION}

Crystals are mainly harvested for the requirements. Researcher has been understanding their properties and to utilize encouraged for the past four decades towards them in this modern word depending upon the NLO. For photonic applications, NLO 
occupies the highest demand. It is frequently said that crystals are dominated by NLO in the scientific fields like laser technology, communication, optical information processing and storage. The researchers come across new NLO materials, it is ought to think that high polarisable organic material plugged into inorganic in order to produce non linear nature of the crystal. The frequency conversion is the source from which combination of optical materials to be decided. One can think for new non linear materials, amino acids bestow a best choice. While concerning amino acids, it showed high optical parametric amplification and second harmonic generation so as to cover the blue and near UV spectral regions [1-5].

Adipic acid is found as a essential substance in chemical industries with high solubility. It can be used as an organic solvent. The adipic acid is recognized as a promising agent to explore the co-crystal formation with imidazole-ring containing molecules [6,7].

Moreover Adipic acid being one type of amino acids which is subjected to present work due to its wide applications in scientific and bio-medical areas. Cobalt nitrate having the molecular formula of $\mathrm{Co}\left(\mathrm{NO}_{3}\right)_{2} \cdot \mathrm{XH}_{2} \mathrm{O}$ is being use as pigments in hair dyer. The search begins to grow new non linear optical materials such as Adipic acid with Cobalt nitrate crystals and their crystallization characters of chiral properties have been investigated.

\section{MATERIAL SYNTHESIS}

The commercially available Adipic acid were taken and dissolved in deionized water. The solution was stirred well with magnetic stirrer till the homogenous solution appeared. Then the solution was filtered and poured in pure glass beaker. Similarly clear solution of Cobalt nitrate was obtained by using the magnetic stirrer. Both these solution namely Adipic acid and Cobalt nitrate are mixed in equimolar ratio stirred well again with magnetic stirrer to receive the clear homogenous mixture and filtered by Whatmann filter paper. The supersaturated solution was allowed to pass in dry beaker and covered tightly with aluminium foil provided with fine holes. Then the solution was allowed to evaporate at a controlled rate without any air disturbance. The nucleation had started and after 60 days developed crystals of Adipic acid Cobalt nitrate (AACON) were taken by forceps. The photograph of AACON crystal is shown in figure 1. The following reaction illustrates the crystal formation. 


\section{$\left(\mathrm{CH}_{2}\right)_{4}(\mathrm{COOH})_{2}+\mathrm{Co}\left(\mathrm{NO}_{3}\right)_{2} \longrightarrow \mathrm{Co}\left[\left(\mathrm{CH}_{2}\right)_{4}(\mathrm{COOH})_{2}\right] \mathrm{NO}_{3}$}

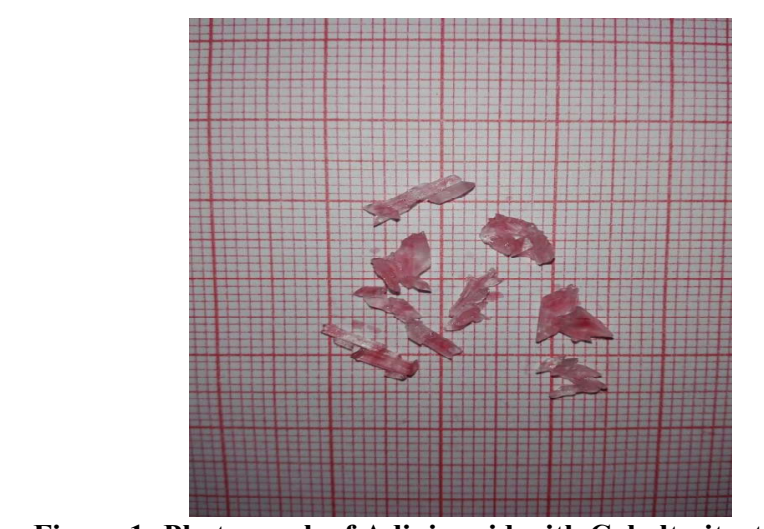

Figure 1: Photograph of Adipic acid with Cobalt nitrate crystals

\section{RESULTS AND DISCUSSION}

\section{UV-Vis-NIR Absorption spectral analyses}

UV-Vis-NIR analysis enlightens the structural details of a grown compound. The recorded absorption spectrum of AACON was recorded using a Perkin Elmer lambda 35 spectrophotometer in the wavelength range of $190 \mathrm{~nm}-1100 \mathrm{~nm}$ [8] which has been shown in figure 2 . The spectral range was chosen in between $200 \mathrm{~nm}$ to $1100 \mathrm{~nm}$ so as to cover the entire visible region, nearinfrared region $\left(4000-13000 \mathrm{~cm}^{-1}\right)$, near UV region. Hence it can be used for optoelectronic applications [9]. The lower cut off wavelength was located at $257 \mathrm{~nm}$. The protuberance was noticed at $300 \mathrm{~nm}$ and $498 \mathrm{~nm}$. The band gap of AACON was calculated as $4.8 \mathrm{eV}$ and acts as a dielectric material which resulted from large number of photons absorption by AACON were assured. The cut off wavelength of AACON finds the requirement for frequency doubling and hence desirable property of non-linear optical material.

\section{UV-Vis-NIR Transmission spectral analysis}

The transmission spectrum of AACON crystal is seen in figure 3 which has the fidelity of providing parameters as a percentage of transmission and transparency cut off for use in laser frequency conversion and optoelectronic devices. The crystal has obviously transparent with $99 \%$ of transmission. Transmission property is evident from the wider optical band gap energy [10].

\section{Fluorescence spectral Analysis}

The fluorescence is non-destructive and fast technique. Fluorescence is found to occur when the interaction takes place between the incident radiations of any kind namely UV or laser with the given sample. 
When the sample is exposed to such radiations of a proper wavelength, atoms or molecules of the sample are excited by absorbing these radiations. Fluorescence finds wide application in the branches of Biochemistry and medicine. It is also used as a lightning in fluorescent lamps, Light Emitting Diode (LED), lamps etc [10-11]. AACON crystal was triggered by fluorescence analysis by using Perkin Elmer LS 45 spectrofluorometer and the obtained spectrum is shown in figure 4. The spectrum was measured in the range of $250 \mathrm{~nm}-800.5$ nm [12]. The intense sharp peak was obtained at $476.98 \mathrm{~nm}$ which lies in blue color in the visible region. The other less intense sharp peaks were obtained at 385.53 $\mathrm{nm}$ (violet emission), $511.35 \mathrm{~nm}$ (green emission), $614 \mathrm{~nm}$ (orange emission), 642 $\mathrm{nm} \& 714 \mathrm{~nm}$ (red emission) of AACON. The optical band gap was computed as 2.6 $\mathrm{eV}$. The excitation wavelength was around $265 \mathrm{~nm}$.

\section{Powder X-ray Diffraction (PXRD) analysis}

The AACON is examined to PXRD analysis and the data's of PXRD were collected. The diffraction pattern is as shown in Figure 5. The powder diffraction pattern was analyzed with $\mathrm{CuK} \alpha$ radiation at wavelength of $1.5406 \mathrm{~nm}$. The crystals were first powdered then scanned in the temperature range of $10^{\circ} \mathrm{C}-80^{\circ} \mathrm{C}$ at a scanned rate of $2^{\circ}$ per/minute values from $12.983^{\circ}$ to $43.044^{\circ}$ The well-defined sharp peak was obtained at $21.5^{\circ}$ shows the pure crystalline nature and homogeneity of the experimental sample material.

FT-IR AND FT -RAMAN Spectral Analysis

FT-IR and FT-Raman spectral analysis of the grown AACON crystal was taken by using Perkin Elmer lambda 35 Fourier Transform Infrared Spectrophotometer. The resultant FT-IR and FT-Raman spectra of AACON were shown in figure (6) and (7). The various functional groups existed were identified by the corresponding peaks in the range of wave number from $400-4000 \mathrm{~cm}^{-1}$ using $\mathrm{KBr}$ pellet technique. Both FT-IR and FT-Raman [13, 14] and their available spectra were compared and verified with literature available and found to be in good agreement which are tabulated and listed in table $1 . \mathrm{CH}$ stretching vibration bands were observed at $2962 \mathrm{~cm}^{-1}$ in FT-IR and $2922 \mathrm{~cm}^{-1}$ in the FTRaman. The Peak 2754 was identified in the FT-IR as C-H stretching. FT-IR band and FT-Raman band were observed for $\mathrm{C}=\mathrm{O}$ 
stretching at $1695 \mathrm{~cm}^{-1}$ and $1647 \mathrm{~cm}^{-1}$ respectively. The peak $1463 \mathrm{~cm}^{-1}$ in FT-IR for $\mathrm{C}-\mathrm{N}$ asymmetric stretching was remarked. C-C stretching $[15,16]$ assignment came out at 1428 in FT-IR and 1435 in FT-Raman for the title compound. FT-IR band for $\mathrm{NO}_{3}$ stretching was at 1358 $\mathrm{cm}^{-1}$. The bands at $1280 \mathrm{~cm}^{-1}$ in FT-IR and $1300 \mathrm{~cm}^{-1}$ in FT-Raman referred $\mathrm{C}=\mathrm{O}$ stretching. The vibration bands of $\mathrm{C}-\mathrm{C}$ stretching were observed at $1044 \mathrm{~cm}^{-1}, 927$ $\mathrm{cm}^{-1}$ in FT-IR and $1047 \mathrm{~cm}^{-1}, 914 \mathrm{~cm}^{-1}$ in FT-Raman. The band at $735 \mathrm{~cm}^{-1}$ in FT-IR noticed $\mathrm{C}-\mathrm{H}$ out of plane deformation. The bands at $689 \mathrm{~cm}^{-1}, 656 \mathrm{~cm}^{-1}$ in FT-IR and FT-Raman were attributed to $\mathrm{C}-\mathrm{O}$ wagging. $\mathrm{C}=\mathrm{C}$ out of plane deformation was obtained corresponding to the bands at $563 \mathrm{~cm}^{-1}$ in FT-IR and $511 \mathrm{~cm}^{-1}$ in FT-Raman. From the data collected, it is found that FT-IR and FTRaman vibration bands meet together; predominantly purity of the AACON was affirmed. The existence of various functional groups present in FT-IR and FT-Raman were derived, indexed and listed in Table 1.

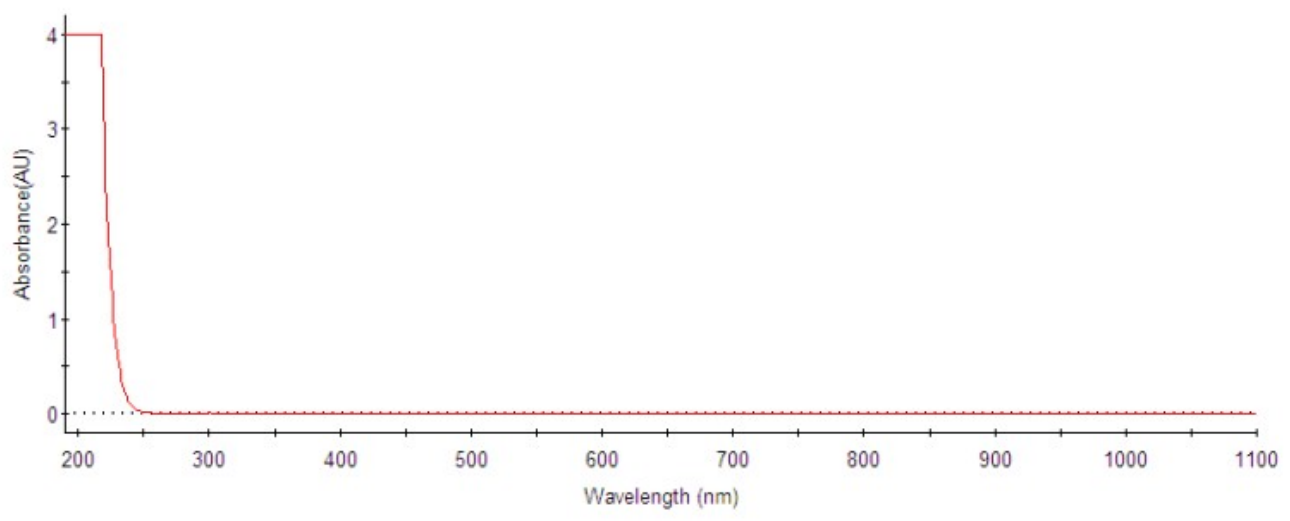

Figure: 2 UV-Vis-NIR spectral analyses of AACON crystal

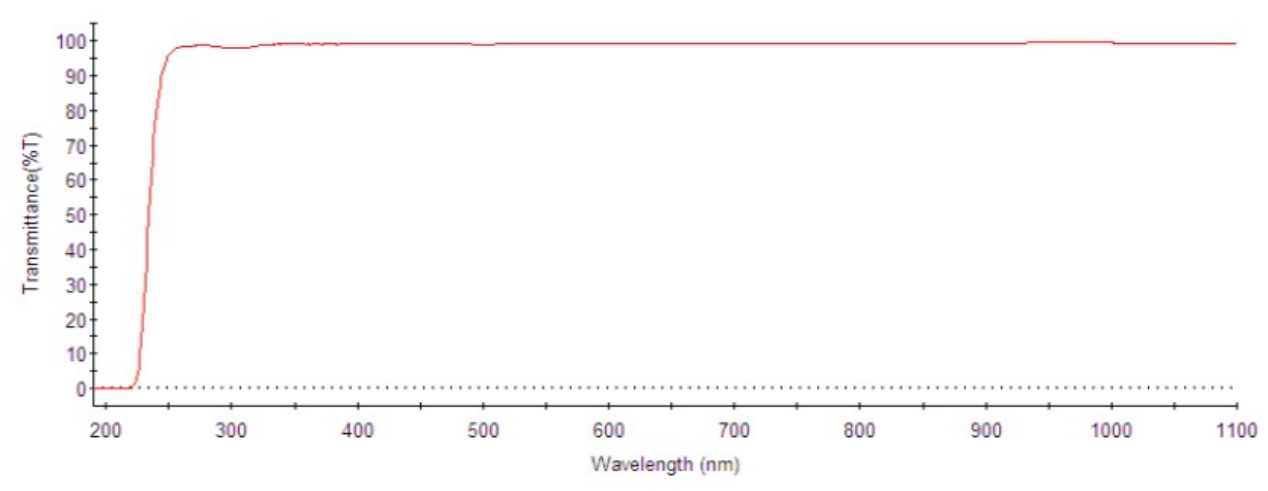

Figure: 3 UV-Vis-NIR spectral analyses of AACON crystal 


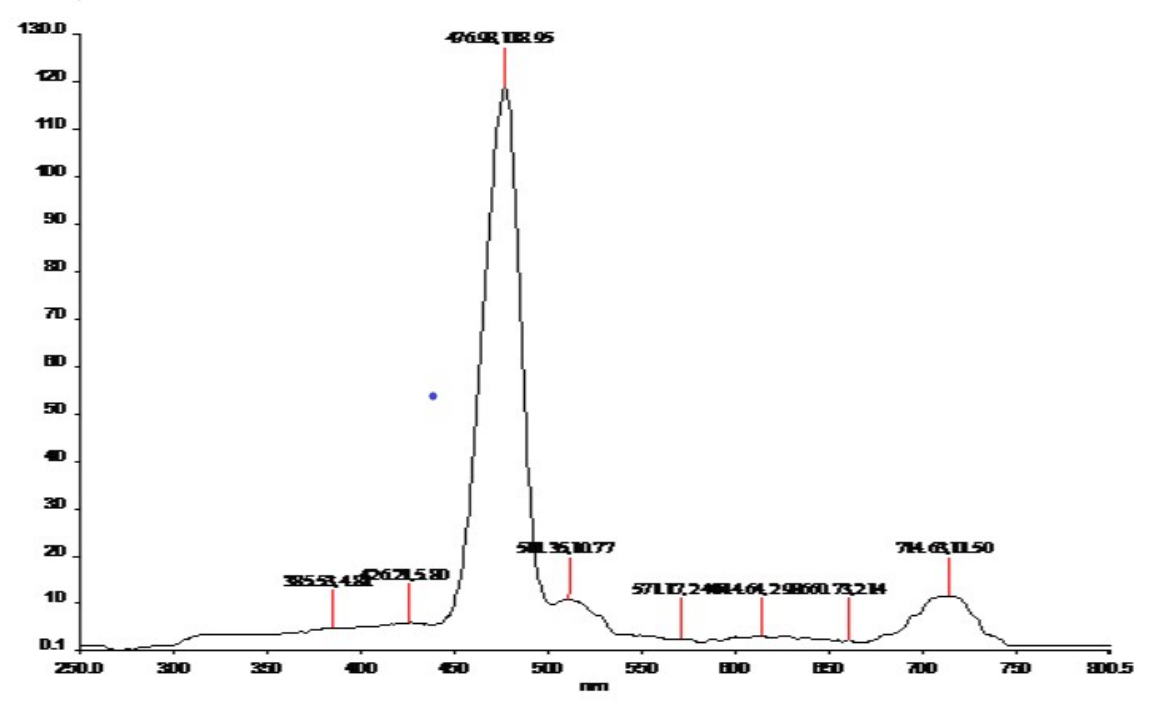

Figure: 4 Fluorescence spectral Analysis of AACON crystal (Coupled TwoTheta/Theta)

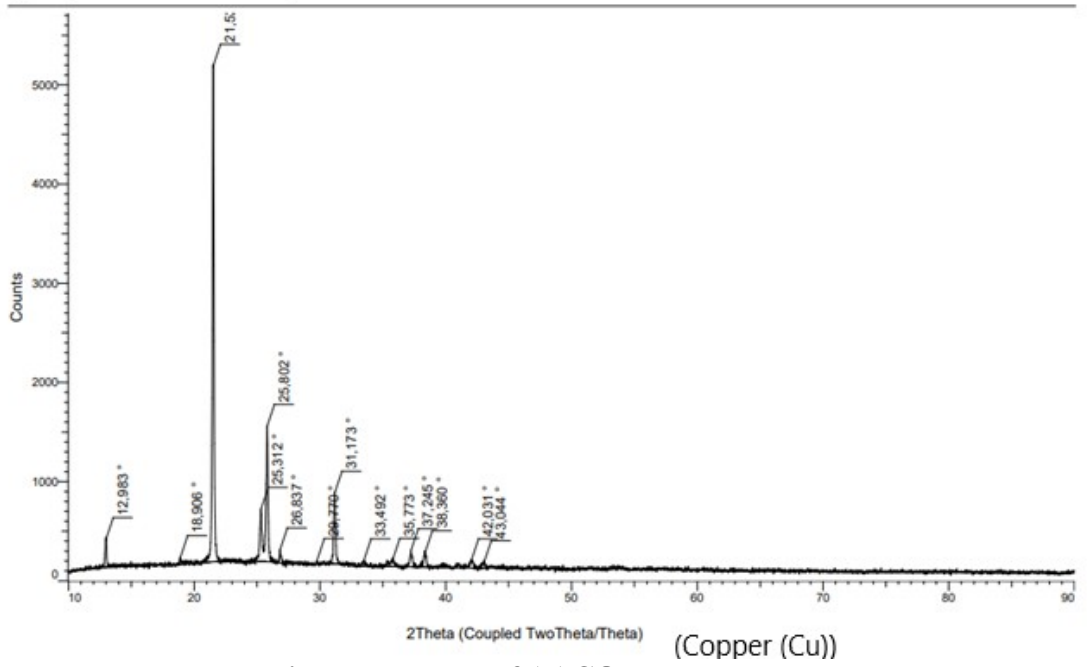

Figure: 5 PXRD of AACON crystal

Table 1: Assignments of vibration frequencies of AACON of FT-IR \& FT-Raman

\begin{tabular}{|c|c|c|}
\hline \multicolumn{2}{|c|}{ Wave Number $\left(\mathrm{cm}^{-1}\right)$} & \multirow{2}{*}{ Tentative Vibration Assignments } \\
\hline AACON(FT-IR) & AACON(FT-Raman) & C-H stretching \\
\hline 2962 & 2922 & C-H stretching \\
\hline 2754 & - & C=O stretching \\
\hline 1695 & 1647 & C-N asymmetric stretching \\
\hline 1463 & - & C-C stretching \\
\hline 1428 & 1435 & NO stretching \\
\hline 1358 & - & C=O stretching \\
\hline 1044 & 1300 & C-C stretching \\
\hline 927 & 1047 & C-C stretching \\
\hline 735 & 914 & C-H out of plane deformation \\
\hline 689 & - & C-O wagging (Cobalt) \\
\hline 563 & 656 & C=C out of plane ring deformation \\
\hline
\end{tabular}




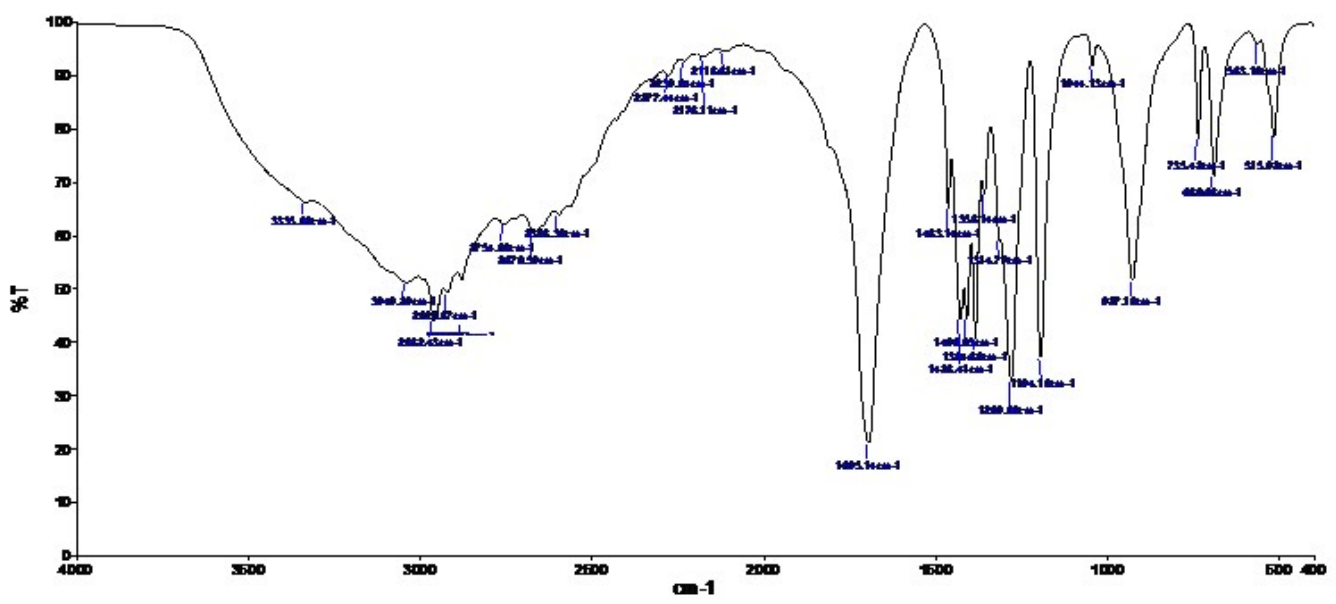

Figure 6: FT-IR spectral analysis of AACON crystal

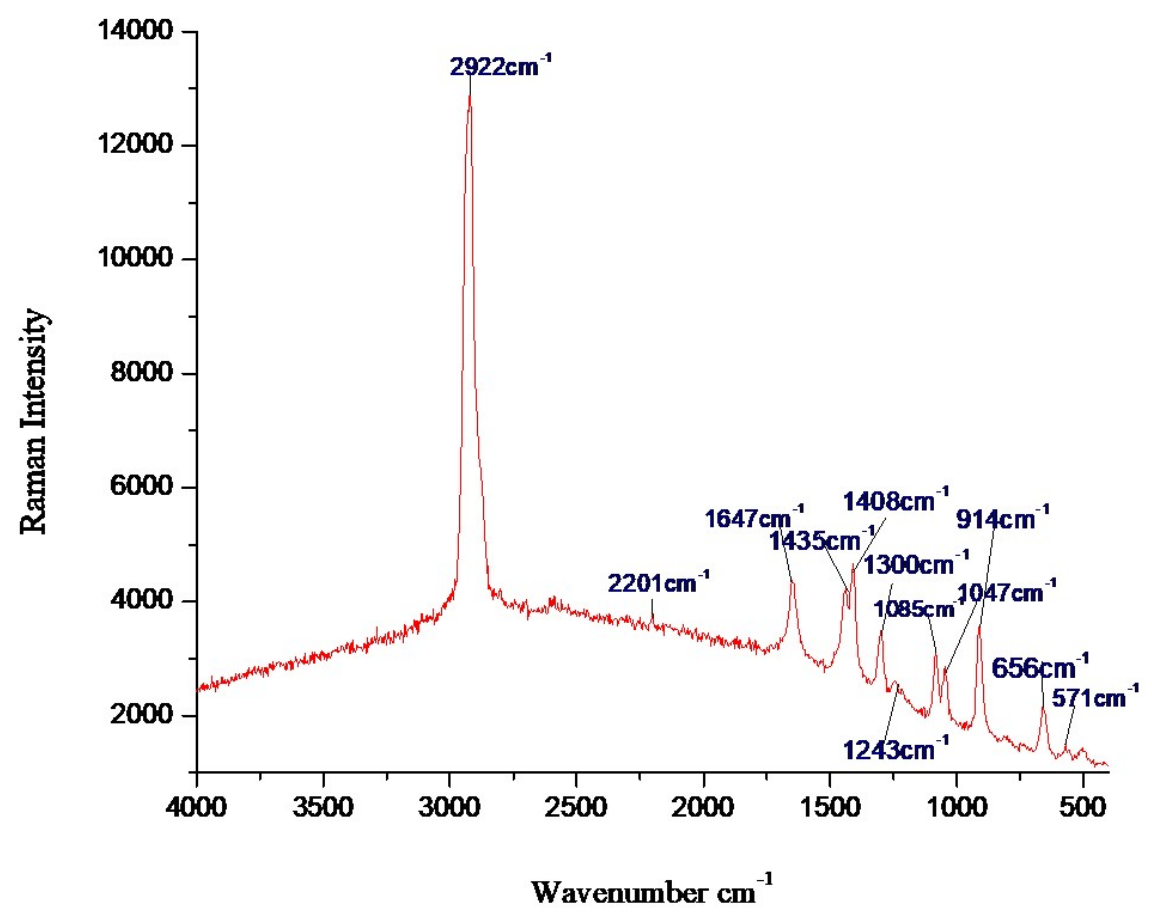

Figure 7: FT-Raman spectral analysis of AACON crystal

Non linear optical studies (SHG Kurtz and Perry [17] using an Nd:YAG laser Efficiency) beam of fundamental wavelength $1064 \mathrm{~nm}$.

The non linear optical property of the The AACON sample was crushed into fine grown crystal was determined by the particles and packed in a micro capillary modified version of powder technique via tube. The title compound was irradiated with 
laser beam of $1.2 \mathrm{~mJ} /$ pulse, at a repetition rate of $10 \mathrm{~Hz}$ with a pulse width of 10ns. The monochromator receive the output beam and transmits only a second harmonic green light at $532 \mathrm{~nm}$ whose intensity was monitored by a photomultiplier tube $[\mathbf{1 8}, \mathbf{1 9}]$ and converted into an electric signal. This signal was obtained in the oscilloscope screen. KDP was takes as a reference material through which SHG conversion efficiency was calculated by the ratio of amplitude of the AACON to that of the KDP signal amplitude recorded for the same input power. The SHG efficiency of AACON crystal is found to 1.07 times greater than that of KDP.

\section{CONCLUSION}

A new semi-organic material of Adipic acid doped with Cobalt nitrate crystal (AACON) has been grown with success by slow evaporation method from homogeneous supersaturated solution at room temperature. The grown title crystals were characterized by different techniques. UV-Vis-NIR studies for AACON crystal suggest that the grown crystal has very good optical absorption and wide transmission in the entire visible region. This ensures the suitability and adaptability of this test compound for optoelectronics applications. Fluorescence studies established that sharp peak corresponding to blue light obtained which in turn used as a blue LED. Moreover the optical band gap was computed as $2.6 \mathrm{eV}$ which signifies the excitation of ions from the lower energy to higher energy by absorption of photons by atoms or molecules of the title crystal confirms the absorption and emission. PXRD peaks confirm the various planes of reflection, good crystalline nature and presence of intermingled compound. FT-IR spectrum reveals the functional groups of crystals. FT-Raman assures the non linear property of the crystal by various peaks corresponding to their various frequency ranges recorded. The emitted spectral lines give the purity of nature of the crystal from FT-Raman studies. SHG efficiency confirms that the AACON crystal has a non linear property in nature whose value is $\mathbf{1 . 0 7}$ times greater than that of KDP.

\section{REFERENCES:}

[1] Haussuhl S., Z. Kristallogr., 196, 47 (1991);

https://doi.org/10.1524/zkri.1991.19 6.1-4.47.

[2] Indumathi N., P. Sanjay, K. Deepa, J. Madhavan and S. Senthil, IOP Conf. Series Mater. Sci. Eng., 360, 012032 (2018); https://doi.org/10.1088/1757899X/360/1/012032. 
[3] Novikova N.E., N.I. Sorokina, I.A. Verin, O.A. Alekseeva, E.I. Orlova, V.I. Voronkova and M. Tseitlin, Crystals, 8, 283 ( 2018); https://doi.org/10.3390/cryst807028 3.

[4] Balamurugan N., M. Lenin and P. Ramasamy, Mater. Lett., 61, 1896 (2007);

https://doi.org/10.1016/j.matlet.200 6.07.184.

[5] Dhavud S.S. and J.T.J. Prakash, Int. J. Adv. Res., 5, 1542 (2017) https://doi.org/10.21474/IJAR01/48 $\underline{68}$

[6] Lesbani, Fitriliana A. and R. Mohad, Indo. J. Chem., 15, 64 (2015);

[7] https://doi.org/10.22146/ijc.21225.

[8] Suren S., N. Sunsandee, M. Stolcva, M. Hronec, N. Leepipatpiboon, U. Pancharoen and S. Kheawhom, Fluid Phase Equilib., 360, 332 (2013);

https://doi.org/10.1016/j.fluid.2013. $\underline{10.003}$.

[9] Northrop Gruman Corporation, Linthicum, Maryland, Ming C.W.U, University of California, Los Angeles, Edward Zellers, University of Michigan, Ann Arbor, "Material Research to Meet 21st century
Defense Needs: Chapter 5: Electronic and photonic materials", pp 95-100, The National Academics of Sciences and Engineering and Medicine, Washington D.C, The National Academic Press, https://doi.org/10.17226/10631.

[10] Vijayan N., R. Ramesh Babu, M. Gunasekaran, R. Gopalakrishnan, P. Ramasamy, R. Kumaresan, C.W. Lan, J. Crystal Growth 249 (2003) 309.

[11] Rao K.V., A.Smakula, J.Appl.Phy.36 (1965) 3953.

[12] Turro N.J., "Molecular Photochemistry", Benjamin, New York. 1965.

[13] Williard HH, Merritt JrLL, Dean JA, Settle JrFA Instrumental methods and analysis, sixth ed., wadworth publishing company, USA. (1986):p.609

[14] Balanagammal $\quad$ S., $\quad$ R. Mahalakshmi, Optic 126 (2015) 5294-5296.

[15] Sandhya Ravi, S. Chenthamarai, "Growth and Characterization of Single Crystals of Thiourea Based .Compounds", 2014, Indian J.Sci.Res. 9(1), (2014); 051-057. 
[16] Shaikha R.N., Mohd, Anisa, M.D. Shirsath, S.S. Hussaini, study on optical properties of L-doped ADP crystal, spectracheimia Acta part a Molecular and Biomolecular spectroscopy, vol.81, (2011); pp, 270- 275.

[17] Masamichi Tsuboi, Tadao Takenishi, Asao Nakamuba. Spectrochim Acta, 19 (1963); 271.

[18] Kurtz S.K., T.T.Perry, J.Appl.Phys.39 (1968) 3798

[19] Saravanan R.R., S.Seshadri, M.Murugan and V. Mannivannan, “ Structural, optical properties and effect of amino acid on growth of KDP crystals", Indian Journal of Pure and Applied Physics, Vol.51, April 2013,pp-254-259. 